\title{
Developing a Better Planning, Budgeting, and Accounting System
}

The primary purpose of budget management is not to only determine what can be done with the resources available, but rather to push a company forward and help achieve goals. At Huawei, budgets are prepared in a way that encourages growth, and budget allocation is aligned with the company's strategy. Planning, budgeting, accounting, and appraisals at all levels of Huawei are managed in a closed loop. Specifically, planning and budgeting play a guiding role, and accounting is used to assess and oversee the execution of plans and budgets.

Huawei links budgets to a department's contributions and strategic importance. If a department belongs to a strategic domain, the company will grant a budget to this department. However, if it is not in a strategic domain, then that department must contribute profits to the company. Those who are in charge of strategic domains must be committed to achieving strategic goals.

Success is the result of proper planning. Huawei requires its planning staff to understand its business. Planning is critical because it is the basis for budgeting. The company aims to gradually shift the focus of its business management from business plans $(\mathrm{BPs})^{1}$ to strategic plans (SPs). ${ }^{2}$

\footnotetext{
${ }^{1}$ Business plans (BPs) are the company's one-year development plans.

${ }^{2}$ Strategic plans (SPs) are company-wide plans that look at mid- and long-term development.
}

(C) The Author(s) 2019

W. Huang, Built on Value, https://doi.org/10.1007/978-981-13-7507-1_11 
At Huawei, there are two approaches to budgeting. For business departments that are responsible for expansion, including R\&D, Sales, and Marketing, the company analyzes whether their detailed budgets are reasonable, rather than simply controlling their budget caps. Other departments are functional departments. Their expenses are fixed, and their total budgets are strictly controlled. The company approaches budgeting for business departments from the bottom up, and for functional departments from the top down.

Huawei plans to gradually put in place an outside-in, profit-centerbased budgeting and final accounting system. Customers and projects are the focus of budgeting work. Operating departments in the field and functional departments at HQ both focus on the company's strategy when planning their own key customer, $R \& D$, and transformation projects. This approach helps Huawei gradually establish a mechanism through which resources are channeled to strategic domains and valued customers.

Huawei separates functional department budgets from project budgets. Its annual budget is prepared based on projects or opportunities. The company has established a budget allocation system based on the "SPproject-budget" logic. Project teams buy resources from supporting departments according to their business plans and granted budgets. Supporting departments are responsible for resource efficiency. Huawei does everything it can to keep the expenses of functional departments as low as possible.

All budgets at Huawei are flexible, including the company's total budget and every individual department's budget. This flexibility aims to ensure field teams can obtain more resources after their business grows.

Accounting is an important indicator of management improvement. At Huawei, the rules for budgeting and accounting are the same. When a certain rule is used for budgeting, this same rule is also used for accounting. This is how the company achieves closed-loop budget management. Huawei focuses more on the most important points when it comes to cross charging for incentive purposes. The goal of this is to reduce the costs of internal transactions.

This chapter elaborates on the above management approaches and principles for planning, budgeting, and accounting. 


\subsection{Aligning Planning, Budgeting, and Accounting with Strategy and Business OpERATIONS}

\subsubsection{The Primary Purpose of Budget Management: Pushing the Company Forward Rather Than Only Determining What Can Be Done with the Resources Available}

Our total budget is the basis for all of the company's business activities over the fiscal year. It is also an important way for us to manage the uncertainties of our external environment, make our decision-making process more methodical and less arbitrary, and improve the overall business performance and management of the company. (Source: The Huawei Charter, 1998)

The micro and macro are not completely disconnected. They are interconnected in one way or another. Budgeting is by no means just a financial, economic, or political issue. This is a very complicated management system. (Ren Zhengfei: Speech at a Work Report on 1999 Budgets, 1999)

The primary purpose of budget management is not to only determine what can be done with the resources available, but rather to push a company forward and help achieve goals. We should aim for sustainable revenue growth. We should constantly explore the rationality of flexible coefficients. These coefficients vary by region and by product domain. Flexible indicators are comprehensive. For example, we can assign different weights to indicators such as contribution gross margin, cash flow, and output, and put them together to obtain a set of flexible indicators. We need to create multiple types of flexible coefficients and gradually achieve scientific management. (Source: Resolution on Strengthening Total Budgeting and Cost Management in the End-to-End Process, EMT Resolution No. [2016] 009)

First, we need to be clear about our goals and responsibilities. After that, we should think about how to achieve these goals and fulfill these responsibilities through planning and budgeting. Budgeting ensures that resources are allocated in a way that supports strategy execution. Before getting started on planning and budgeting, we must know the general direction in which we are going and do the right thing following the direction. It is also important to understand the opportunities available to us and the things that need to be managed. Only then can we figure out 
how to get to where we want to go. Budgeting is very important, but it is not an easy job. It requires much more than working on one's own. Budgeting needs to be flexibly linked to goals and adjusted based on those same goals. Its contributions to results need to be determined through final accounting. (Ren Zhengfei: Focusing on Strategy and Streamlining Management, Huawei Executive Office Speech No. [2012] 041)

Budgets must be prepared in a way that encourages growth, enabling flexible resource allocation based on rolling business forecasts. Budgets should also encourage improvement and growth in individual departments. Huawei cannot adopt a one-size-fits-all approach to rigidly strike a balance among different departments. Planning, budgeting, accounting, and appraisals at all levels of the company should be managed in a closed loop. Specifically, planning and budgeting will play a guiding role, and accounting will be used to assess and oversee the execution of plans and budgets. At Huawei, operations management relies on a cycle of forecasting, planning, budgeting, and accounting. Managers who impede the company's ongoing improvements to data sharing, data transparency, and data quality should be transferred to the work group responsible for integrating data in their respective domains. (Ren Zhengfei: Minutes of the Meeting on the Budgeting Work, Huawei Executive Office Speech No. [2014] 004)

\subsubsection{Establishing a Planning, Budgeting, and Accounting System to Support Business Success}

At the corporate level, product lines represent a vertical line of planning, and regional offices represent a horizontal line of planning. Together, they form a matrix management system for planning, budgeting, and accounting. The purpose of establishing such a system is to support business success. The system should serve regional presidents, general managers of representative offices, and presidents of product lines, and should support their business success. The basic units of planning, budgeting, and accounting management are regional offices, representative offices, and product lines. Business planning authority should be delegated to these basic units. Managers of these basic units should use this methodology to direct business operations. (Ren Zhengfei: Minutes of the Meeting on Developing a Planning, Budgeting, and Accounting System, EMT Meeting Minutes No. [2007] 024) 
Planning, budgeting, and accounting are not tasks performed solely by the planning, budgeting, and accounting departments. They are part of regional, representative office, and product line businesses. Planning and budgeting departments serve as the secretariat that helps regional offices, representative offices, and product lines put together plans and strike an overall balance to support their business operations. (Ren Zhengfei: Minutes of the Meeting on Developing a Planning, Budgeting, and Accounting System, EMT Meeting Minutes No. [2007] 024)

The plans for regional offices, representative offices, and product lines are used to facilitate business operations while the plans for HQ are used for macro forecasting and controls. (Ren Zhengfei: Minutes of the Meeting on Developing a Planning, Budgeting, and Accounting System, EMT Meeting Minutes No. [2007] 024)

When you work alone on a project without any instructions, staying profit-centered will always be the right thing to do. You have every right to work this way. If you don't receive any instructions for a project, you can certainly center your actions on profits. We think that regional offices have the authority to independently make decisions in such cases, as long as you stay profit-centered. However, when it comes to strategic issues, you need to report them to higher-level management and ask for instructions. Strategic issues often sacrifice short-term interests in exchange for long-term interests. If you do not ask higher-level management for instructions, who will subsidize your short-term losses? In addition, strategic issues are not that urgent, and you have plenty of time to report them, so you must follow certain procedures. (Ren Zhengfei: Remarks After Watching the Battle of Moscow-Speech at the Egypt Representative Office, Huawei Executive Office Speech No. [2008] 004)

I believe that good numbers are a result of good work; good numbers cannot be faked. We must focus our energy on analyzing the market and serving our customers. If we work hard to get our job done, I don't think we will get bad numbers. The planning system on the front lines is designed to facilitate business operations, not to report back to HQ. The regional office and product line plans have the same purpose. Frontline departments must have a clear direction and the right strategy for success. Regional offices that fail to reach the average compound annual growth rate of the company can focus more on fine-grained management. Departments that do not work on the front lines must provide highquality services to the front lines by continuously improving themselves 
through fine-grained management. (Ren Zhengfei: Speech at the EMT ST Meeting on January 31, EMT Meeting Minutes No. [2008] 009)

We should first choose small countries to develop highly competent, lean teams. These countries are too small to maintain large teams anyway, so all of their resources have to come from back offices. That will make it easy for small countries to call for support. The key issues we need to address are: Who will provide the support? And how will it be accounted for? We should run a pilot program in small countries. We can correct any problems we might run into during the process of calling for support. Once the pilot program is successful, we can work out a model and apply it in medium-sized and then big countries. Whether big countries should have an independent platform can be talked about later. (Ren Zhengfei: Building Lean Teams in Small Countries First; Allowing Field Teams to Call for Support-Speech at the Report of the JCR's Regions Management Department on Approaches to Small Country Operations, Huawei Executive Office Speech No. [2015] 126)

\subsubsection{Linking Budgets to Contributions and Strategies}

Our market investment budgets should continue to be based on relative numbers. We can gradually align budgets with business targets based on the historical patterns of change in our expense/revenue ratios so that increases in business expenses, especially customer-facing expenses, align with sales growth. We need to use different expense/ revenue ratios for emerging and mature markets. (Ren Zhengfei: Comments at the Meeting Regarding the Planning and Budgeting Work for 2005, 2004)

Business departments work hard to achieve their sales targets. We can therefore use these targets as a reference for resource allocation, but they should not be the sole basis. We should not rigidly allocate resources based on sales targets, as this may cause waste. Business departments should make commitments based on practical goals and get the resources needed to achieve those goals. Resources needed to achieve stretch goals should be allocated to business departments in phases rather than on a one-off basis. Otherwise, business departments will set lower targets for their KPIs. Reserve resources in the company must be covered with the company's overall budget, and their budgets will not be allocated to business departments. Otherwise, things will get complicated. The budgets for all flexible items will be listed separately and covered in the company's overall 
budget. (Ren Zhengfei: Comments at the Meeting Regarding the Planning and Budgeting Work for 2005, 2004)

Budgets must be linked to a department's contributions and strategic importance. If your department is in a strategic domain, we will grant a budget to you. However, if it is not in a strategic domain, then you've got to contribute profits to the company. Those who are in charge of strategic domains have to take an oath, pledging to achieve strategic goals. They should have a timetable for everything they do. Any modifications to business plans should be clearly explained, and money should be well spent. When a department applies for a budget, they must clarify their responsibilities and contributions. After approval is obtained, the results they deliver and the responsibilities they assume will be used as the most important basis for performance appraisals. (Ren Zhengfei: Focusing on Strategy and Streamlining Management, Huawei Executive Office Speech No. [2012] 041)

We should gradually put in place an outside-in, profit-center-based budgeting and final accounting system. Investments in BGs and SBGs ${ }^{3}$ are determined by their output, and investments in functional departments at HQ are determined by the total output of the company. HQ's authority and size should be adapted to the company's organizational transformation in which those closest to customers can call for support. Representative offices should be our accounting centers. All expenses must come from representative offices. The authority to prepare and approve budgets cannot both be in the hands of HQ. Otherwise, HQ will become increasingly bloated. When we shift our focus to representative offices, HQ should help representative offices win key projects. They can even send people over to representative offices. In this way, they can earn money from representative offices, and the extra labor hours claimed by representative offices will come back to HQ. Budget committees must comprise of people from both business and finance departments. Our current problem is that tasks often cannot be completed even though we are spending money on them. We must clarify how compensation packages are generated. For example, how much should packages be based on where we are in executing a plan? Compensation packages should be based on business results, and then HR can further divide the packages. (Source: Requirements for Continuing to Streamline the Organization to Improve Efficiency and Productivity, EMT Resolution No. [2012] 026)

\footnotetext{
${ }^{3}$ Service Business Groups (SBGs) are business operations centers that provide services.
} 
During total budget management, we must be very clear about our stance against the following conduct: making irrational final sprints to achieve KPIs, intentionally covering up business results for accounting or incentive purposes, and voluntarily giving up opportunities to achieve better results. We must create the right values and encourage teams to work hard and forge ahead. Business resources are primarily allocated and managed in two ways. First, we have a resource allocation plan. The total resources of the company are fixed. Those who contribute more will receive more resources. Second, resources will be allocated based on profits. We have different profit requirements for different businesses. If we want a business to develop faster, we will reduce its burden by setting lower profit requirements. If a business is too risky and inflated, the profit requirements will be higher. We will calculate the business results of profit centers based on the profit and cash flow requirements set for each BG and $\mathrm{BU}$, and strike an overall balance between collecting profits and investing resources within the company. The Finance Committee will manage the end-to-end process in a closed loop by focusing on the total amount of investment, the opportunities created by such investment, and the results achieved. (Guo Ping: Effectively Managing Corporate Value to Pursue Sustainable and Profitable Growth, Huawei Executive Office Speech No. [2012] 005)

When we build our business strategic reserve pools, we should develop vertically rather than horizontally. Otherwise, we will have to cut projects and waste money. As for the HR reserve pool, we can set aside a budget provided by HQ to develop the elite teams, the Key Project Department, and the Project Management Resource Pool. Elite teams should participate in global projects to seize the strategic high ground. If they win, their costs can be charged to projects. If they lose, they have to take care of the costs themselves, with the budgets provided by HQ. This approach will allow the company to reinforce the fine tradition of "toasting those who succeed and offering a helping hand to those who fail". (Ren Zhengfei: Speech and Comments at the Carrier BG's 2013 Strategy Retreat, Huawei Executive Office Speech No. [2014] 016)

\subsubsection{Shifting the Focus of Business Management from BPs to SPs}

We will implement a new management system to delegate more authority to field offices. The purpose of this is to greatly increase our work 
efficiency and make sure field offices command back offices. We now make it clear that executives should command field teams when it comes to strategic issues; for tactical issues, field offices should command back offices, and back offices should provide full support to field offices. If back offices cannot provide services to field offices, they have no reason to exist in the first place. Strategic issues should be decided upon by executives at HQ because these issues normally involve sacrificing shortterm interests in exchange for long-term interests. Such sacrifices should be reflected in the financial statements of the beneficiaries and be backed up by executives. (Ren Zhengfei: Speech at the 2008 Mid-year Report by Regions to the EMT, EMT Meeting Minutes No. [2008] 028)

If an overly rigid approach is adopted in performance appraisals, strategic goals will be affected. In the future, we will specify our strategic positioning in our general principles. We must plan and set strategic goals, which should be assessed in phases. (Ren Zhengfei: Speech at the EMT ST Meeting on April 29, 2010)

We should improve our capabilities in mid- and long-term strategic planning and strategy management at the company level as well as in BUs, marketing units (MUs), ${ }^{4}$ and functional units (FUs). ${ }^{5}$ We should shift the focus of our business management from BPs to SPs. This will better guide executives to focus on long-term strategies, perform regular strategy reviews, and arrange for work reports. It will also help regional offices, product lines, and other departments better collaborate with each other to ensure that strategies are well aligned and actions are consistent with strategies. Closed-loop management for SPs and BPs should be linked to performance appraisals of executives and financial planning of the company to ensure that the SPs and BPs are executed. (Source: Huawei's 2011 Work Priorities, EMT Resolution No. [2011] 019)

We must adopt different budgeting models for product investment to support strategic products and control products that are not in the core business. For strategic products, five-year R\&D budgets will be approved on a one-off basis based on the company's SP cycle and will be granted on an annual basis. For products that are not in the core business, we will adopt Smartcom's model, whereby the profit goals are higher, and the profit that is above the average product profit can be allocated to $R \& D$

\footnotetext{
${ }^{4}$ Marketing units (MUs) are regional or customer-facing departments.

${ }^{5}$ Functional units (FUs) are departments that provide specialized support for business operations.
} 
investments. For non-strategic products in our core business, resources will be allocated based on annual budgets. (Ren Zhengfei: Minutes of the Meeting on the Budgeting Work, Huawei Executive Office Speech No. [2014] 004)

\subsubsection{Establishing a Budget Allocation Mechanism Based on the "SP-Project-Budget" Logic}

HQ does not have its own budget, as all resource budgets are in projects. Once the field calls for resources, we will deploy resources there, whose costs will be charged to the field. We need to change the current budget allocation method by granting the budget to the field. HQ has to get the budget it needs from projects by providing services. This is the only way we can downsize HQ. (Ren Zhengfei: Integrating Project Estimation, Budgeting, Accounting, and Final Accounting to Support Project Operations-Speech at a Briefing on the IFS Project, Huawei Executive Office Speech No. [2010] 007)

We need to separate functional department budgets from project budgets, and keep the expenses of functional departments as low as possible. The goal of functional department operations is to ensure that we promptly deliver high-quality products and services to customers at affordable prices. When functional departments support a project, they need to ask the project manager to pay for their work, and this payment can be deducted from the project budget. By taking this approach, functional departments will try to have the project manager pay for expenses, and the project manager will try their best to control project expenses through the efficient use of resources from functional departments. This will result in conflicts, but a balance will be achieved in the end. The purpose of establishing such a mechanism is to make sure HQ provides services to the field and charges them for these services. (Ren Zhengfei: Integrating Project Estimation, Budgeting, Accounting, and Final Accounting to Support Project Operations-Speech at a Briefing on the IFS Project, Huawei Executive Office Speech No. [2010] 007)

Currently, our budgeting is about granting funds to functional departments. It's a process of distributing authority among departments at various levels. Those who have budgets have authority. We will not be able to change our current situation if we don't change the owner of authority and the way budgets are generated. We must be clear about the sources and recipients of budgets and how budgets can be used to support strategy 
execution. (Ren Zhengfei: Rigorous, Well-ordered, and Simple Management Is Crucial for Huawei to Scale New Heights, Huawei Executive Office Speech No. [2014] 028)

Departments have always believed that, for their budgets, "what is in place is rational". They think if they had a budget the previous year, they should have one this year too. Now both resources and money are in the hands of functional departments. However, departments that fight on the front line do not have money, and they have to ask functional departments for budgets. We started to change this practice last year. Our R\&D budgets are no longer granted to product lines. Instead, they will first be granted to the IRB ${ }^{6}$ and IPMT so that budgets can be allocated to projects that can create value and execute strategy. As for accounting, we have to define our accounting units first, as that will make many things clear. (Ren Zhengfei: Rigorous, Well-ordered, and Simple Management Is Crucial for Huawei to Scale New Heights, Huawei Executive Office Speech No. [2014] 028)

We must transform our budget management system based on responsibility centers. Customers and projects must be the focus of our budgeting work, and our budgets should also be prepared in a way that helps create sustainable value and make contributions. By preparing budgets, we aim to execute business strategy and achieve business goals while aligning authority and interests with responsibilities. Budgets must be prepared in a way that encourages growth, and budget allocation must be aligned with our company's strategy. We must establish a budget allocation system based on the "SP-project-budget" logic. With this system, operating departments in the field and functional departments at HQ will both focus on the company's strategy when planning their own key customer, R\&D, and transformation projects. This approach will help us gradually establish a mechanism through which resources are channeled to strategic domains and valued customers. (Guo Ping: Transform Continuously and Improve Field Operating Capabilities to Ensure the Company's Sustainable and Profitable Growth-Speech at Huawei Annual Management Conference 2013, Huawei Executive Office Speech No. [2014] 020)

We will optimize our rules for managing resource department budgets so that they only have budgets given by HQ. Other resource department

\footnotetext{
${ }^{6}$ The Investment Review Board (IRB), formerly known as the Product Investment Review Board, is a team that manages Huawei's investment portfolios, decision making, and end-toend collaboration involving products and solutions for different industries.
} 
budgets must be earned by supporting projects that request their resources. In this way, budgets will be used to facilitate business operations. These decisions only need to be approved by those who have budgets. Adopting this approach will allow our operations to shift from being functioncentered to being project-centered. (Guo Ping: Transform Continuously and Improve Field Operating Capabilities to Ensure the Company's Sustainable and Profitable Growth-Speech at Huawei Annual Management Conference 2013, Huawei Executive Office Speech No. [2014] 020)

We stress that projects should have management authority and that resources come with a cost. (Ren Zhengfei: Focusing on Strategy and Streamlining Management, Huawei Executive Office Speech No. [2012] 041)

\subsection{Preparing Plans and Budgets FROM THE BOTTOM UP}

\subsubsection{Projects and Customers: The Focus of Planning, Budgeting, and Accounting}

When preparing plans and budgets, we must prioritize field teams and projects. Project planning, budgeting, and accounting must be accurate. All project managers must take planning, budgeting, and accounting seriously. Effectively using projects as the basic unit to manage planning, budgeting, and accounting is the foundation of managing and appraising regional offices as profit centers. (Ren Zhengfei: Minutes of the Meeting on Developing a Planning, Budgeting, and Accounting System, EMT Meeting Minutes No. [2007] 024)

Project accounting units can be broken down into regional offices and product lines. We must ensure that after project planning, budgeting, and accounting are effectively managed, regional offices, product lines, and HQ departments can build on and support such work. This is why we need to develop a planning, budgeting, and accounting system at both field and back offices. (Ren Zhengfei: Minutes of the Meeting on Developing a Planning, Budgeting, and Accounting System, EMT Meeting Minutes No. [2007] 024)

Since our profits come from customers, our budgets should also come from customers. Only when we create an accurate budget for customerfacing sales teams can we break the budget into reliable, accurate annual budgets for product lines and regional offices. The rules for budgeting 
and accounting should be the same. When we use a certain rule for budgeting, we also need to use this same rule for accounting. This is how we achieve closed-loop budget management. (Ren Zhengfei: Focusing on Strategy and Streamlining Management, Huawei Executive Office Speech No. [2012] 041)

\subsubsection{Proper Planning: Integrated Operating Plans Are the Foundation of Effective Management}

Success is the result of proper planning. We need to break plans down to those who implement them and ensure they understand their tasks. Only when information is passed down accurately can we ensure effective execution at all levels. Managers must make their goals, intentions, methods, standards, and measures understood by their subordinates. Managers should be held accountable if their subordinates don't understand. (Ren Zhengfei: Seizing Historic Opportunities and Welcoming Huge Development in 1998, 1997)

The forecasts made by our planning system are not curves. Data cannot be fully relied upon to make completely accurate forecasts. During execution, we can adopt a breakdown method to get a complete and rational plan. However, forecasts and high-level management of plans rely on intuition. This intuition often doesn't come from economic performance or market orders, but from other things. Sometimes, for example, it is based on an understanding of politics. Reliable contract forecasts must be based on estimations, tracking, and analysis. Our employees must become more sensitive to the factors involved. (Ren Zhengfei: Strengthening Management of Revenue to Drive Productivity and Revenue Increase, 1998)

How can we achieve fine-grained management? The key is to have a reasonable plan and avoid being blind. Proper planning can significantly reduce freight costs and travel expenses for engineers. Success is the result of proper planning. Those who make plans must understand our business. Regional offices need to establish a planning, budgeting, and accounting department, which must be headed by someone who knows our business. Planning is critical because it is the basis for budgeting. Plans and budgets can then be corrected and measured through accounting. Why can't we keep freight costs under control? If we have a good plan and raise the proportion of our ocean shipping, our freight costs will go down. (Ren Zhengfei: Speech at the Report by the BT Account Department and the UK Representative Office, Huawei Executive Office Speech No. [2007] 015) 
The key to reducing backlogs at customs and warehouses lies in developing accurate and objective plans. Regional offices and representative offices must step up efforts to build their planning system. Regional presidents and representative office general managers should be the primary owners for planning. (Source: Guidelines for Delivery, Working Capital Management, and Team Building, EMT Meeting Minutes No. [2008] 013)

When we establish over 20 planning units, what will be the role of level-1 planning committees in the company? They will be responsible for macro-level control, becoming involved in forecasting and planning and guiding future development and basic capability improvement. Our HR policies must be adjusted to support planning. The planning department is more than a financial department. A plan is like a lighthouse, the bow of a ship, and the radar that guides the entire company forward. Our appraisal and reward mechanisms are implemented to help the company forge ahead. The planning department needs to talk with the HR department to figure out how our HR policies should be developed to help us implement plans. We must change our mindset and understand that the planning department represents the entire company, not just the financial department. (Ren Zhengfei: Speech at the 2008 Mid-year Report by Regions to the EMT, EMT Meeting Minutes No. [2008] 028)

When making plans, each business unit should use scientific tools that have restrictive functions and reflect the company's management philosophy. This way, they can create plans that are rational, objective, and fact-based. These restrictive tools include positive cash flow, growth in profits, and an increase in per-capita efficiency. (Source: Minutes of the Report on Developing Plans and Budgets for 2009, EMT Meeting Minutes No. [2008] 036)

The purpose of our transformation in warehouse management is to integrate all warehouse management processes. Simplifying our supply model requires that our site plans are developed correctly on their first try. In the future, our supply centers will go digital and we will gradually reduce the number and scale of supply centers. If we can't make accurate plans for shipping equipment to sites, how can we develop an accurate plan for shipping equipment to warehouses in representative offices? The number of base stations is small in small countries, so we should think harder about how to develop the right models that can ensure our data accuracy. (Ren Zhengfei: Speech at the Report on the Integrated Management Transformation in Small Countries, Huawei Executive Office Speech No. [2014] 062) 


\subsubsection{Making Business Forecasts Move Reliable}

Business plans are the most important thing we look at when creating annual budgets. We must reasonably allocate resources through annual forecasting and promptly adjust resource allocation based on business forecasts. This is the primary cycle of operations management. To manage expenses effectively, we must begin with closed-loop budget management. We must first check whether the expenses are within the scope of the approved budget and then check whether the expense baselines are reasonable or not. If expenses exceed the budget, there are two scenarios: If the business plan has changed, new opportunities have emerged, or there are unexpected risks, you can apply for a new budget. On the other hand, if there are no changes to the business plan, the expenses that exceed the budget will be covered by the administrative team (AT). (Meng Wanzhou: Aligning Financial Settlements with Value Creation and Aligning Cross Charging for Incentive Purposes with Value Distribution, Huawei Executive Office Speech No. [2012] 040)

Over the next five years, we aim to achieve 3.0 points in information management maturity. This is an important part of data governance. It means we need to ensure that all of our business data comes from a single source and is therefore traceable and that our business forecasts are reliable. (Source: Minutes of the Report on Data Work, EMT Meeting Minutes No. [2014] 024)

We will identify and manage business risks through rolling forecasts and business reviews, and then flexibly adjust resource allocation. The head of each responsibility center is the owner for making forecasts. (Source: 2015 Budget White Paper, Finance Committee Notice No. [2014] 014)

The reliability of forecasts reflects the overall capabilities of managers at all levels. So long as there is no significant change to budget assumptions, any huge deviation of actual and forecasted numbers in the short term from the annual budgets tells us that managers are not good at forecasting. For departments where forecasts deviate greatly from their annual budgets, the revenue and profits beyond their budgeted numbers should be included in the departments' contributions. However, during performance appraisals, the managers' ability to prepare budgets and make forecasts should be considered. (Source: Minutes of the Meeting on the 2016 Q1 Performance Review, Finance Committee Meeting Minutes No. [2016] 019) 


\subsubsection{Continuously Optimizing Expense Baselines, Reducing Operating Costs, and Improving Management to Increase Efficiency}

Cost management: Focusing on cost structures to control costs in the end-to-end process

In the coming three to five years, our most important task will be to improve our management and increase our efficiency. Right now, our percapita efficiency is only one-sixth of IBM's. Can we increase it to one-third or even half of IBM's within three to five years? If so, we will be realizing an enormous amount of potential and improve our core competencies. We must improve our management and increase efficiency. This is the only way to sustain and grow the company's business. (Ren Zhengfei: Staying Prepared Against Adversities in Times of Peace and Working with Stamina and Diligence-Speech at the Work Meeting of the Technical Support Department, 1999)

We cannot control management costs in just a few domains. Cost controls need to be pursued in the end-to-end process. We should focus on cost structures and analyze the costs of big domains and large departments. Don't focus on the costs of small projects. If we keep a tight grip on their costs, bottlenecks will be created. If we use our current review method, no small projects will pass review because none of them are profitable. Opportunities, market size, and market share are all financial data. The cost management department should not aim to control and cut down on costs, but to provide guidance. This department should let go costs that should not be controlled and provide guidance on how to control costs that should be controlled. The cost management department must not just do paperwork. It must identify the actual issues. Cost control is necessary, but it must not affect our strategy. (Ren Zhengfei: Minutes of a Work Report on Annual Taxes and Budgets, 2001)

Cost controls are mainly about providing guidance for cost management in business departments based on the company's overall goals. This work should be about providing concepts, awareness, and methods to business departments, which will make adjustments and figure things out by themselves while keeping in mind the company's overall goals and interests. (Ren Zhengfei: Minutes of a Work Report on Annual Taxes and Budgets, 2001)

We must study how feudal dynasties in China were overthrown. It often did not cost a new emperor much to overthrow the previous one 
because the children of the previous emperor often formed a huge parasitic class that dragged the empire down. The new emperor would, in turn, have dozens of children, each of whom would have their grand residence and needed to be supported by the dynasty. Dozens of generations later, this group of "parasites" would become too large for the country to bear. Following this cycle, eventually civilians overthrow the beleaguered dynasty. Each dynasty shared the fate of their predecessors. If Huawei follows this same path, it will not be long before it goes bankrupt. (Ren Zhengfei: Guidelines for Human Resources Management Transformation, 2006)

Separating functional department budgets from project budgets and keeping functional department expenses as low as possible

We need to separate functional department budgets from project budgets, and keep the expenses of functional departments as low as possible. The goal of functional department operations is to ensure that we promptly deliver high-quality products and services to customers at affordable prices. (Ren Zhengfei: Integrating Project Estimation, Budgeting, Accounting, and Final Accounting to Support Project Operations-Speech at a Briefing on the IFS Project, Huawei Executive Office Speech No. [2010] 007)

We will spend three to five years reducing our general and administrative (G\&A) expense rate so that our sales, general, and administrative (SG\&A) expense rate can match Ericsson's current status. How can our SG\&A expense rate be reduced? We cannot simply go about it like wringing water from a towel. We need to build long-term mechanisms to continuously improve efficiency by optimizing our organizational structures and processes and automating our IT systems. (Source: 2010 Key Work Requirements, EMT Resolution No. [2010] 007)

Can we streamline our organization or not? The answer is yes. There is sure to be a lot of unnecessary work being done, such as asking and waiting for unneeded instructions before doing something, sending all sorts of emails, and holding unnecessary meetings. This is a great waste of time and energy and costs us a lot. We need to adopt a unified platform for our operations and let the department head take charge of everything. If things go wrong, the head will be held accountable afterwards. We will complete this task in three to five years and increase Huawei's overall efficiency by $20 \%$. I think we have a good chance of achieving that. If we can do this, we will be able to increase our profit without the need to increase the price we charge our customers. We will not have to transfer our internal 
costs to customers by charging them higher prices. We should cut down on our internal costs based on market prices rather than set the prices for customers based on our internal costs. (Ren Zhengfei: Speech and Comments at the Strategy Retreat on Competition and Cooperation, 2012)

We must gradually shift from the existing process compliance system into a process ownership system. Warehouse management is a real mess under our existing process compliance system. Who is to blame? Why not distribute the scrapped engineering materials to you as your bonus? It is our unswerving principle to hold wrongdoers accountable, even for acts that were committed in the past. Those who falsify accounts or cause waste and loss will see the equivalent amount of money deducted from their bonuses. If the bonus for a given year is insufficient to cover the losses they cause, the money will be deducted from their bonuses for the next several years. If a representative office general manager who was involved in the misconduct has left their position, they will still be held accountable, and will be given a "negative bonus". This way, they will learn the lesson and improve. Only by doing this will we have a better future. (Ren Zhengfei: Speech at a Meeting with Trainees at the First Training Session for the Project Management Resource Pool, Huawei Executive Office Speech No. [2014] 058)

\subsection{Implementing Flexible Budgeting to Adapt to Opportunities And Changes}

\subsubsection{Reasonableness Analysis of Detailed Business Department Budgets and Strict Control of Functional Department Budget Caps}

We should approach budgeting for business departments that are responsible for expansion from the bottom up. Their budgets will be granted as long as they are reasonable. We also need to check whether their budgets are spent reasonably. People responsible for preparing budgets must become deeply involved in business departments so they can accurately check whether their detailed budgets are reasonable. If we simply increase the percentage of our R\&D budget in total revenue without controlling or overseeing how the money is spent, the money may not be well spent. The budgeting department must check whether the detailed budgets for business departments are reasonable. The budget and headcount for 
functional departments must be controlled. We will squeeze the "excess water" out of the towel. General and administrative expenses must not increase at the same pace as our revenue. Functional departments must control their budgets from the top down. (Ren Zhengfei: Speech at a Work Report on 1999 Budgets, 1999)

There are two approaches to budgeting. For business departments that are responsible for expansion, including R\&D, Sales, and Marketing, we need to analyze whether their detailed budgets are reasonable, rather than simply controlling their budget caps. Other departments are functional departments. Their expenses are fixed, and their total budgets are strictly controlled. Budgeting should vary by department. We should approach budgeting for business departments from the bottom up, and for functional departments from the top down. (Ren Zhengfei: Speech at a Work Report on 1999 Budgets, 1999)

We will grant resource budgets to field offices, and profit centers will cover those expenses and costs. HQ does not have any money; it only has a minimum budget to ensure its operations. HQ has to charge field offices for the services it provides. Our budget should be prepared from the bottom up. Who should call for support? Field operating teams, not managers in back offices. This support comes at a cost. Those who call for support should bear associated costs. (Ren Zhengfei: Keeping Customer PO Information Transparent to Support Payment Collection, Revenue Recognition, and Project Budgeting and Accounting-Speech at a Work Report by the IFS Project Team on December 29, Huawei Executive Office Speech No. [2009] 002)

There are bottlenecks at our company's HQ. We should reduce the authority of HQ and downsize the HQ platform. HQ must focus on providing services. They cannot have all the budgets and resources in their hands, and have all the say about where the budgets and resources go. This must change. We must build a budgeting and final accounting system based on profit centers. This year, you have decided that HQ expenses cannot increase. My requirement is that the total expenses at HQ decrease next year. If the expenses don't decrease, we will have to let some people go or cut salaries. We can also have all HQ staff take a one-month break to see whether our field teams can continue to get their job done. If the answer is yes, it means HQ is not that important, and should be downsized. (Ren Zhengfei: Speech at the Self-reflection Session of the Executive Committee of the Board of Directors, 2012) 
We have to set compensation baselines for HQ and control costs at HQ. To make this happen, our HR department needs to develop the necessary policies. (Ren Zhengfei: Speech at a Briefing on the Progress of the ISC+ and CIF Projects, Huawei Executive Office Speech No. [2017] 035)

\subsubsection{Preparing Flexible Budgets to Allow Field Teams to Obtain More Resources After Their Business Grows}

All budgets must be flexible, including the company's total budget and every individual department's budget. We must gradually figure out the ratios between the total budget of the company and individual departments' budgets. (Ren Zhengfei: Comments at the Meeting Regarding the Budgeting Work for 2004, 2004)

We need to change from inflexible to flexible budgeting. When our business grows, the budget should increase accordingly. We also need to improve HQ's efficiency in providing services. They should complete all necessary approvals within a standard time frame to ensure that field teams can quickly obtain more resources they need after their business grows. (Source: Minutes of the Meeting on Preparing for the Development of a Planning and Budgeting Audit Management Committee, EMT Meeting Minutes No. [2006] 021)

What does it mean to delegate planning, budgeting, and accounting authority to regional offices? It means we will give you a plan and you must pool resources together according to that plan. Resource expenses should not exceed your budget. Accounting will be performed when the budget is used up. If sales volumes increase dramatically, your budget will soar as well. However, if you use up your budget, but your sales volume doesn't go up, that means you are incapable. If you don't spend any money, though, you will be unable to grow your market. How do we make informed decisions based on the specific circumstances around us? We need to have the right managers. They must be able to flexibly control actual business situations. If they lack flexibility when using the plan and budget, it will be impossible for them to be good managers. We will delegate planning, budgeting, and accounting authority to regional offices. It would be unscientific and unreasonable for us to apply the same standard allocation rate to all regional offices. The planning department should not only take care of planning, but also perform accounting to carry out closed-loop management. After accounting is done, we will explore different allocation rates for different products, countries, and regions. After that, our performance appraisal criteria will become clear. (Ren Zhengfei: 
Speech at the 2008 Mid-year Report by Regions to the EMT, EMT Meeting Minutes No. [2008] 028)

We must gather experience in flexible budget management. For example, if your plan increases and profits grow, and you still have to get your headcount and compensation approved, how can the budget be flexible? If your business results improve, budgets will increase naturally, and you will be able to operate on your own. However, if your business results worsen, you need to cut your budget immediately. (Ren Zhengfei: Speech at a Briefing of the Northern Latin America Region and Colombia Representative Office, Huawei Executive Office Speech No. [2014] 051)

We must not do business around the world rigidly. Instead, we should adopt flexible strategies and tactics. Right now, we are not investing enough in many of the strategic opportunities we face, but are expending lots of energy on areas where we have no hope. This is wasting our strategic resources. (Ren Zhengfei: Minutes of the Briefing on the Progress of Differentiated Appraisals for Regions, Huawei Executive Office Speech No. [2015] 050)

We must continuously analyze the difficulties we face in all the countries where we operate, and find the right operating model for each country. Seeking to expand in all countries will cost a lot, and those costs will be passed on to other countries. This approach is too rigid. For regions where we have no room for further expansion, we must transfer our strategic forces away to strategic regions with more opportunities. When the environment improves and opportunities emerge, we can transfer our strategic forces back. In war-torn countries where conditions do not permit network construction, we can provide spare parts and services at higher prices so we can support our local employees. If our business shrinks in countries where we face extreme hardships, we need to strengthen our process-based management. This will make it possible to oversee business operations in these countries remotely. (Ren Zhengfei: Minutes of the Briefing on the Progress of Differentiated Appraisals for Regions, Huawei Executive Office Speech No. [2015] 050)

Our current flexible budgeting system does not effectively use the huge profits we earn. To effectively manage our profits, we must consider linking our SPs and BPs. We need to systematically and strategically plan longterm investment based on the company's financial forecasts for the next three to five years. In addition, we must develop a sound plan that guides on the pace and intensity of our investment based on annual business results. (Source: Minutes of the Meeting on the 2016 HI Performance Review, Finance Committee Meeting Minutes No. [2016] 032) 


\subsubsection{Strictly Implementing a Process for Granting and Increasing Budgets}

Huawei has always worked to lower operating costs and expenses. Through continuous improvements, we aim to increase efficiency, improve management, and boost profitability. Since the IT industry's last "hard winter", we have been very lax with our closed-loop budgeting and accounting management. Sometimes we don't even set a limit on expenses. Managers at all levels just want to hire more people. They are never worried about whether they have money or not. They never care about how much they have spent or assess the relationship between the money spent and the value and contribution it created. Operating costs and expenses are very flexible. While continuing to use a flexible bottom-up budgeting system, we also need to build a strict closed-loop budgeting and accounting management system to avoid manager-driven budget granting and management. (Source: Resolution on Strengthening and Improving Administrative Expense Management, EMT Resolution No. [2008] 032)

We are now doing a better job at managing expenses. However, we still need to reinforce our work in developing a long-term closed-loop budgeting and accounting management system. In particular, we must strictly implement a process for granting and increasing budgets. Our goal is to achieve flexible budgeting and flexible management and ensure that money is available only when a budget is in place. (Source: Minutes of the Report on the 2009 HI Performance Review, EMT Meeting Minutes No. [2009] 038)

Every department has its responsibilities, and all work within the scope of their responsibilities must be supported by the department's budget. Departments cannot apply for an additional budget for work that falls within their normal scope of responsibilities. Department budgets must be managed in a closed loop. The annual budgets should be generated based on responsibilities, expense baselines, and management improvement requirements. Resources will be allocated based on budgets. If resources beyond the budget are needed, the department involved must specify what extra things they need to do and what value will be created. The extra budgets can be listed separately and the company will centrally generate and grant these budgets. These extra budgets will not be included in departmental budget baselines. (Ren Zhengfei: Minutes of the Meeting on the Budgeting Work, Huawei Executive Office Speech No. [2014] 004) 


\subsection{ACCOUNTING: An IMPORTANT INDicATOR of Management Improvement}

\subsubsection{Overseeing the Exercise of the Delegated Authority Through Accounting to Ensure Field Teams Have Command Authority}

At HQ, we should streamline our organization and keep our processes simple. We should reduce direct command and remote control from HQ, move command centers to field offices, and give field teams the authority to perform their own planning, budgeting, and accounting. This means we are delegating the management and sales decision-making authority to field offices. Field offices need to have more tactical mobility to flexibly deal with changes in actual situations. Back offices need to step up their efforts to provide services based on plans and budgets, and oversee the exercise of delegated authority through accounting. This can make sure field teams have the authority they need to get the job done and HQ doesn't need to worry about the authority being abused. (Ren Zhengfei: Speech at the UK Representative Office, Huawei Executive Office Speech No. [2007] 027)

The key to budgeting lies in closed-loop budget management through accounting. Whether departments have taken budgeting seriously and have prepared their budgets effectively is determined through the accounting and assessment of their actual business results. (Ren Zhengfei: Minutes of the Meeting on the Budgeting Work, Huawei Executive Office Speech No. [2014] 004)

Currently, the amount of resources a field team needs to win a project still needs to be approved by HQ. For example, when a field team asks for nine people, HQ may only send six people over, claiming six people are enough. However, with the six people, the field team might not be able to fully win the project. In the future, we should delegate authority to the field and provide whatever they request. After the battle is over, we can calculate the amount of resources used for the project. For example, we may find out that only three of the nine people sent over by HQ actually worked on the project, so we need to check with the field team where the other six people have been. We are still unable to implement such an authority delegation system because we have not yet achieved end-to-end project management. We will ultimately get there within the next five to ten years. (Ren Zhengfei: Remarks to Candidates for Full-time Board 
Directors at the Board Director Enablement Workshop, Huawei Executive Office Speech No. [2014] 007)

\subsubsection{Improving Management Through Scientific Accounting}

The primary purpose of implementing independent accounting is to improve management through comprehensive accounting. Currently, accounting does not cover all aspects of our operations. Through comprehensive accounting, we aim to encourage departments to focus more on costs and numbers. (Ren Zhengfei: Minutes of a Briefing on the Operating Mechanism of the Mechanical \& Industrial Division, 1998)

When we track IPD and ISC projects, accounting is of paramount importance. It is really not an easy task to do accounting throughout the IPD and ISC processes. The most important responsibility of Finance in IPD and ISC projects is to do a good job in accounting. If accounting is done properly, we will be able to accurately break down costs that can be used as the basis for project assessments. Currently, Finance should focus its attention on accounting to provide reliable data as an input for management. (Ren Zhengfei: Speech at a Briefing on Four Unifications and 2000 Work Plan of Finance, 1999)

$\mathrm{HR}$ and Finance must do a good job in project cost accounting related to personnel. I simply don't understand why we can't do accounting effectively. When you said the SAP system didn't allow us to do accounting, we switched to the Oracle system. But now we're still having trouble with accounting even two years after the switch. Management improvement at Huawei will be impossible if our personnel expenses are not charged directly to projects. We should strengthen the guiding role of planning, budgeting, and accounting in our business development. The accounting of personnel expenses doesn't have to be too accurate. Estimated numbers are also acceptable. (Ren Zhengfei: Adapting the Manager Appraisal System to Challenges Facing the Transforming Industry, Huawei Executive Office Speech No. [2006] 036)

Accounting is an important indicator of management improvement. It's impossible to know whether we are making progress if we don't do accounting. We need to first perform accounting by project, region, and product line. Thanks to our core value of inspiring dedication in our employees, we are very competitive now. This management philosophy works for Huawei. However, our current management efficiency is very low. (Ren Zhengfei: Timely, Accurate, High Quality, and Low Cost Delivery 
Calls for Professional Process-compliant CFOs-Minutes of a Meeting with Trainees of the CFO Session of the Reserve Pool, Huawei Executive Office Speech No. [2009] 021)

We don't have to do extremely fine-grained accounting for everything. For example, whether accounting should be performed down to the last component depends on the applicable business scenario. For material purchases, it is of course necessary to account for costs down to the last component. But for engineering delivery and product sales, we only need to account for the revenue or cost at the site or device level. Considering the complexity of some forms of accounting, we are still not mature enough to achieve the granularity we should have, so I think properly investing more resources in this is the right thing to do. (Ren Zhengfei: Minutes of the Meeting with Staff of the Romania Accounting SSC, Huawei Executive Office Speech No. [2011] 021)

We must reinforce our management of customer- and supplier-facing roles and make related estimation, budgeting, accounting, and final accounting more effective. These are the sources of our profits. We need to follow our major processes to improve management and accounting of the resources called for by field offices, keep costs under control, and improve the quality of operations to ensure profitability. To manage expenses effectively, we should properly manage budgets and ensure that expenses are reasonable and compliant with applicable laws and regulations. We should focus more on the most important points when it comes to cross charging for incentive purposes. The primary purpose of financial management is to generate profits and eliminate corruption. (Ren Zhengfei: Focusing on Strategy and Streamlining Management, Huawei Executive Office Speech No. [2012] 041) 
Open Access This chapter is licensed under the terms of the Creative Commons Attribution-NonCommercial-NoDerivatives 4.0 International License (http:// creativecommons.org/licenses/by-nc-nd/4.0/), which permits any noncommercial use, sharing, distribution and reproduction in any medium or format, as long as you give appropriate credit to the original author(s) and the source, provide a link to the Creative Commons licence and indicate if you modified the licensed material. You do not have permission under this license to share adapted material derived from this chapter or parts of it.

The images or other third party material in this chapter are included in the chapter's Creative Commons licence, unless indicated otherwise in a credit line to the material. If material is not included in the chapter's Creative Commons licence and your intended use is not permitted by statutory regulation or exceeds the permitted use, you will need to obtain permission directly from the copyright holder.

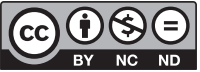

